\title{
Atypical teratoid/rhabdoid tumor of the central nervous system
}

\author{
Beatriz de León-Bojorge • Fernando Rueda-Franco • \\ Marcial Anaya-Jara
}

Received: 8 June 2009 / Published online: 28 July 2009

(C) Springer-Verlag 2009

\section{Dear Editor:}

We have read with interest the article by Ertan et al. [1], published in Child's Nervous System, about "Atypical teratoid/rhabdoid tumor of the central nervous system: clinicopathologic and immunohistochemical features of four cases". However, in the paper, we do not found any figure related with the immunohistochemical features, as stated in the title.

In the March 2008 issue of Child's Nervous System, we published an article on the same subject, reporting on ten cases [2]. In our paper, we included three examples of immunohistochemical markers, emphasizing the importance of this method in the diagnosis of these lesions. Unfortunately, however, the authors did not include it in their references.
Anyway, their series are similar with ours and with others in the literature: Those children have a dismal prognosis.

\section{References}

1. Ertan Y, Sezak M, Turhan T, Kantar M, Ersahin Y, Mutluer S, Vergin C, Öniz H, Akalm T (2009) Atypical teratoid/rhabdoid tumor of the central nervous system: clinicopathologic and immunohistochemical features of four cases. Childs Nerv Syst 25:707-711

2. De León-Bojorge B, Rueda-Franco F, Anaya-Jara M (2008) Central nervous system atypical teratoid rhabdoid tumor: experience at the National Institute of Pediatrics, Mexico City. Childs Nerv Syst 24:307-312

B. de León-Bojorge $\cdot$ F. Rueda-Franco $\cdot$ M. Anaya-Jara $(\bowtie)$ Department of Pathology, National Institute of Pediatrics, Insurgentes Sur 3700-C Col. Insurgentes-Cuicuilco,

Del. Coyoacán,

CP 04530 Mexico, Mexico

e-mail: marcial7@hotmail.com 